\title{
Age at death, the return of an old metric whose importance is growing
}

\author{
Jean-Marie Robine ${ }^{1,2} \mathbb{D}$
}

Received: 30 August 2018 / Accepted: 31 August 2018 / Published online: 21 September 2018

(c) Springer Nature Switzerland AG 2018

The age at death is rarely used by demographers and epidemiologists except for the calculation of life expectancy at birth. Yet age at death provides unique information that is becoming increasingly important as we are experiencing the longevity revolution.

In a paper published in 2010, Gill and colleagues identified five end-of-life disability trajectories among American individuals who died after age 70, opposing people who had lived without disability until the end of their life $(17 \%$ of deaths) to people who died after a long period of severe disability, lasting at least 1 year (21\% of deaths) [1]. The former died on average 4 years earlier (at 82.8 years versus 86.8 years) and were more often men, whereas the latter were more often women. Causes of deaths differed between these two extreme groups: sudden death was more likely in the first group, with average age at death 82.5 years, whereas "frailty" and "advanced dementia" were more common in the second group, with average age at death 85.7 and 87.3 years, respectively. Here, the age at death combined with the disability trajectory during the last year of life strongly suggests the existence of a trade-off between quantity and quality of lived years. This is one of the most important issues we have to deal with as life expectancy increases.

Analyzing the distribution of the age at death of parents, to distinguish short-, intermediate-, and long-lived groups of parents, several recent studies have shown that those who had parents who had lived for a long time had a lower incidence of diabetes, heart disease, stroke, and even cancer [2] as well as a lower incidence of cognitive decline [3]. They were better protected from risk for coronary artery disease,

Jean-Marie Robine

Jean-marie.robine@insem.fr

1 MMDN, EPHE, Unité Inserm 1198, PSL Research University, Université de Montpellier, Bâtiment 24, Place Eugène Bataillon-CC105, 34095 Montpellier Cedex 05, France

2 CERMES3, UMR CNRS 8211-Unité Inserm 988-EHESS, Université Paris Descartes, 94801 Paris, France systolic blood pressure, body mass index, cholesterol, and triglyceride levels than others [4, 5] and had lower risks of incident peripheral vascular disease, heart failure, or atrial fibrillation [6].

Another example is the excess mortality observed in 2015 compared to previous years [7, 8]. It was mainly attributed to influenza and people aged 65 and over [9]. The death statistics now available by detailed age show, for example in France, that the increase in the total number of deaths of 34,767 deaths between 2014 and 2015 corresponds in fact to an increase of 38,095 deaths for the total ages who see the number of deaths increasing and a decrease of 3328 for the total of others. These 38,095 actually additional deaths occurred on average at 81.9 years for men $(+16,660$ deaths) and 89.3 years for women $(+21,905$ deaths $)$ while at the same time the number of elderly from 96 to 100 years, belonging to the depleted cohorts from 1915 to 1919 , decreased sharply. This decline cannot be compensated for by the low fertility rebound of 1920 and 1921. Hiam and his colleagues found comparable results for England and Wales where the excess mortality mostly concerned those aged over 85 years [10]; see 11 for more information. All of these examples show the importance of age at death as a metric.

In a precedent issue of this journal, Menotti and colleagues looked at the age at death of the 1712 men living in Italian rural areas who participated in the seven countries study in 1960 [12]. Fifty years after enrollment, i.e. in 2010, $97.5 \%$ of them were dead. But of what and at what age? The results were quite paradoxical. Those who had the lower level of risk in 1960 (never smoker, following a Mediterranean diet, having a vigorous physical activity) were the ones who lived the longest but they died of senility or poorly defined causes. The mean age at death was 75.0 years. They considered 12 groups of causes of death. Cardiovascular causes and cancers were responsible for $45.8 \%$ and $27.6 \%$ of the deaths, respectively. Two groups appeared like outliers: heart diseases of uncertain etiology with a mean age at death of 79.2 years and senility or causes unknown with a mean age at death of 84.5 years. While the standard deviation of 
the age at death is quite large, \pm 11.2 years in total, it was far lower for senility and the unknown causes, with 7.2 years. Together, these two groups of ill-defined causes account for $17 \%$ of deaths occurred since 1960 . For men belonging to cohorts aged 40-59 years in 1960, who were born in Italy between 1901 and 1920, these ages at death are very high. According to birth year, between 1901 and 1920, their life expectancy ranged from 46 to 52 years. At age 80 , only $18-26 \%$ survived and at age 85 only $9-17 \%$ [13].

As explained by the authors, at the start of a longitudinal study, it is interesting to focus on the relative risk of mortality (odd ratios) according to various initial risk factors, measured for instance at ages of 50 or 65 . But at the end of a long follow-up when almost all participants are dead, it is much more interesting to look to the mean age at death according to these same risk factors and to the reported causes of death.

In summary, these studies, using the ages at death as a core metric, reveal the complexity of the relationship between age and health. On the one hand, having parents who have lived long for their birth cohort or not having been exposed to the major known risk factors guarantees a long life. On the other hand, having a long life increases the risk of ending life with a long period of frailty, disability and dementia. Reaching a high age at death does not mean being in good health at a very advanced age or at the time of death; it means that we have been healthier than others and for longer. This is the complexity of the relationship between age, health and quality of life. This trade-off must be understood before deciding to privilege, at all costs, longevity.

Demographers are focusing today on mortality rates and epidemiologists on relative risks but this has not always been like this. Historically, ages at death have been analyzed well before mortality rates which assumed a count of exposed populations. When finalizing the calculation of life expectancy at the end of the nineteenth century, the main interest was still in the ages at death and their distribution, following the work of Adolphe Quételet (1796-1874). Wilhelm Lexis (1837-1914) thus distinguished three distributions within deaths, infant mortality, adult mortality due to aging which is normally distributed around 72 years, and premature mortality that extends between these first two distributions [14]. Jacques Bertillon (1851-1922) acknowledged, in his discussion of the Lexis paper, the conceptual and methodological progress achieved. Deaths are concentrated immediately after birth and around a maximum circa $72 / 73$ years old but in the calculation of life expectancy at birth we lose this information. In France, life expectancy was then about 40 years, "although it is precisely one of the ages when death occurs most rarely" [15]. However, with the priority given to the fight against infant mortality in the early twentieth century, life expectancy at birth will be regarded as the best and most satisfactory index of lifespan [16]. We had to wait until the first years of the twenty-first century to see the interest for the distribution of the ages at the death relaunched by Vaïno Kannisto (1916-2002) which unearthed the works of Lexis [17]. In the meantime interest in the average age at death as a natural indicator of typical longevity has continued to grow.

The most recent and the most innovative approaches focus on differences in the distribution of ages at death between occupational categories or causes of death. Thus, van Raalte and her colleagues have shown that lower educated individuals not only have shorter life expectancies, but also face greater uncertainty about the age at which they will die [18]. She also showed the weight of early adult mortality among Finnish manual workers. Their study suggests that mortality compression of mortality is compatible with an increase in life expectancy but currently only achieved by higher occupational classes [19]. This result was recently extended to Denmark by Brønnum-Hansen using income data [20]. Diaconu and her colleagues focused on the causes of death. They revealed important differences in the ages at death between the leading causes of death with the greatest gap between lung cancer and cerebrovascular and heart diseases. In 2011, in Canada, the female modal age at death from lung cancer was 77.8 and that from heart diseases 91.2, a 13.4-year gap [21].

\section{Compliance with ethical standards}

Conflict of interest The author declares that he has no conflict of interest.

Statement of human and animal rights This article does not contain any studies with human participants performed by the author.

Informed consent For this type of study formal consent is not required.

\section{References}

1. Gill TM, Gahbauer EA, Han L et al (2010) Trajectories of disability in the last year of life. N Engl J Med 362:1173-1180

2. Dutta A, Henley W, Robine JM et al (2014) Aging children of long-lived parents experience slower cognitive decline. Alzheimers Dement 10:S315-S322. https://doi.org/10.1016/j. jalz.2013.07.002

3. Dutta A, Henley W, Robine JM et al (2013) Longer lived parents: protective associations with cancer incidence and overall mortality. J Gerontol A Biol Sci Med Sci 68:1409-1418

4. Pilling LC, Atkins JL, Bowman K et al (2016) Human longevity is influenced by many genetic variants: evidence from 75,000 UK Biobank Participants. Aging (Albany NY) 8:597-613

5. Pilling LC, Kuo C-L, Sicinski K et al (2017) Human longevity: 25 genetic loci associated in 389,166 UK biobank participants. Aging (Albany NY) 9:2504-2520 
6. Atkins JL, Pilling LC, Ble A et al (2016) Longer-lived parents and cardiovascular outcomes: 8-year follow-up in 186,000 UK Biobank Participants. J Am Coll Cardiol 68:874-875

7. Bellamy V (2016) 594000 personnes décédées en France en 2015: plus de décès hivernaux qu'en 2014. Insee Focus-No 65 $(13 / 10 / 2016)$

8. Signorelli C, Odone A (2016) Dramatic 2015 excess mortality in Italy: a $9.1 \%$ increase that needs to be explained. Scand J Public Health 44:549-550

9. Mølbak K, Espenhain L, Nielsen J et al (2015) Excess mortality among the elderly in European countries, December 2014 to February 2015. Eurosurveillance 2015;20(11). pii $=21065$. http:// www.eurosurveillance.org/ViewArticle.aspx?ArticleId=21065

10. Hiam L, Dorling D, Harrison D et al (2017) Why has mortality in England and Wales been increasing? An iterative demographic analysis. J R Soc Med 110:153-162. https://doi. org/10.1177/0141076817693599

11. Robine J-M (2017) When climate change encounters the revolution in adult longevity. Aging Clin Exp Res 29:1073-1074. https ://doi.org/10.1007/s40520-017-0839-z

12. Menotti A, Puddu PE, Maiani G et al (2018) Age at death as a useful indicator of healthy aging at population level: a 50-year follow-up of the Italian rural areas of the Seven Countries Study. Aging Clin Exp Res 30:901-911

13. Human Mortality Database (2018) https://www.mortality.org. Accessed 23 Feb 2018
14. Lexis W (1878) Sur la Durée Normale de la Vie Humaine et sur la Théorie de la Stabilité des Rapports Statistiques. Ann Démogr Int 2:447-460

15. Bertillon J (1878) Discussion of Lexis's paper «Sur la Durée Normale de la Vie Humaine et sur la Théorie de la Stabilité des Rapports Statistiques ». Ann Demogr Int 2:460-461

16. Dublin LI (1923) The possibility of extending human life. Metron 3:175-197

17. Kannisto V (2001) Mode and dispersion of the length of life. Population 13:159-171

18. van Raalte AA, Kunst AE, Deboosere P et al (2011) More variation in lifespan in lower educated groups: evidence from 10 European countries. Int J Epidemiol. https://doi.org/10.1093/ije/dyr14 6

19. van Raalte A, Martikainen P, Myrskylä M (2014) Lifespan variation by occupational class: compression or stagnation over time? Demography 51:73-95. https://doi.org/10.1007/s1352 4-013-0253-x

20. Brønnum-Hansen H (2017) Socially disparate trends in lifespan variation: a trend study on income and mortality based on nationwide Danish register data. BMJ Open 7:e014489. https://doi. org/10.1136/bmjopen-2016-014489

21. Diaconu V, Ouellette N, Camarda CG et al (2016) Insight on 'typical' longevity: an analysis of the modal lifespan by leading causes of death in Canada. Demogr Res. https://doi.org/10.4054/DemRe s.2016.35.17 